\title{
El aprendizaje basado en problemas y la genuina realidad. Diario de un tutor
}

Luis A. Branda

'Sé como el ruiseñor, que no mira a la tierra desde la rama verde donde canta'.

(R. Valle-Inclán, La lámpara maravillosa)

Hay gran abundancia de publicaciones sobre el aprendizaje basado en problemas (ABP), pero lo que es difícil encontrar en ese cenagal de información es una descripción de la 'genuina realidad' de la experiencia docente. William James acuñó el término 'genuina realidad' refiriéndose a la conjunción distributiva 'ahora': cuando un conferenciante habla a su audiencia, puede decir, 'ahora miro al frente, ahora miro a la izquierda, ahora miro a la derecha y veo en cada caso diferentes caras. Es el conjunto y no sólo lo que ven mis ojos cuando mi mirada se fija en una dirección lo que refleja la genuina realidad. El consejo que da Valle-Inclán en una de sus 'normas' -que aparece en el epígrafe- parece ser la equivocada actitud de muchos trovadores del ABP: salmodiar las bellas estrofas del ABP sin mirar hacia la genuina realidad que está abajo, en la tierra. El confrontar la 'genuina realidad' no significa ver solamente lo peor de nuestras experiencias; el júbilo, el sentirse realizado, son emociones tan reales como lo son los momentos más sombríos y oscuros de ella. Una mejor comprensión de la 'genuina realidad' no debe desalentarnos o desmoralizarnos; esa comprensión hace más significativos nuestros pequeños triunfos y los placeres cotidianos de nuestras experiencias. Solamente mirando hacia lo que es la realidad y teniéndola en cuenta, se puede hacer una implementación efectiva y además verse la fascinación de esta estrategia de aprendizaje.

También son abundantes las definiciones de lo que es el ABP, pero el intentar dar una definición esencial de algo que sólo puede explicarse a través de una experiencia propia es casi un sofisma. Por ello, puede ser más informativa la descripción de la 'genuina realidad' que transpira de las páginas del diario de un docente que ha registrado su experiencia como tutor novato en el ABP.

El escribir un diario es un proceso psicológico en el cual su construcción y su rol simbólico en la vida del diarista se ha transformado en una cura literaria de su padecimiento. Se atribuye a Platón el decir que la escritura de un diario es un pharmakon, es decir, una medicina pero también un veneno. El narrar nuestras experiencias puede llegar a atormentarnos. Sin embargo, lo que nos atormenta no son las imágenes o palabras, sino la naturaleza de la propia experiencia que está detrás de la narrativa. ¿Por qué este tutor registró en las páginas de un diario su experiencia en el ABP? Probablemente, la lectura del diario no dé la respuesta a la pregunta, aunque sería razonable deducir que las emociones que despierta el involucrarse en esta estrategia educacional podrían ser un factor determinante. Además, el escribir un diario es una manera de hacer una examen de conciencia a solas.

\section{Septiembre. Lunes, 7}

Vacilo al escribir estas notas porque temo ser demasiado analítico para poder hacer justicia a la experiencia que vivo a través del ABP. Lo que siento es difícil de plasmar en el papel porque las palabras que pueda usar-como es la naturaleza de todas las palabras- limitan y pueden tergiversar lo que se supone que deben describir.

En la casa de campo de la pequeña villa toscana donde pasamos las vacaciones el verano pasado, alguien había dejado una copia de ese clásico que, al final del siglo xIX, escribieron los hermanos George y Weedon Grossmith: The Diary of a Nobody. Ese diario es una relación de la minucia de la vida de un personaje que decide escribir un diario a pesar de que no se considere ser 'alguien'. La lectura de este
Unidad de Educación Médica. Facultad de Medicina. Universitat de Girona. Girona, España.

Correspondencia: Prof. Luis A. Branda. Facultad de Medicina. Universitat de Girona. Emili Grahit, 77. E-17071 Girona.

E-mail:

luis.branda@udg.edu

(c) 2011 Educación Médica 
diario con los detalles de la vida de un miembro de la clase media inglesa debería moderar o quizás inhibir totalmente el emprender una tarea que conlleva el riesgo de provocar el aburrimiento mortal de un posible lector. Sin embargo, siempre ha sido mi costumbre hacer anotaciones de hechos, personas y reflexiones sobre mis experiencias y por ello este diario -que más que un diario es un cuaderno de notas- es la continuación de una costumbre arraigada en mí. No espero que alguien llegue a leer este diario y por eso no me preocupa tener en cuenta que el lapso de atención del lector determine la extensión del cuaderno de notas. Sin embargo, si las circunstancias llevaran a que un día haya un lector de este diario, espero que sea tolerante y acepte mi entendimiento con los que son de la opinión que la escritura puede constituirse en un texto cerrado y definitivo que potencia el dogmatismo y que solamente transmite saber pero no permite el cuestionamiento de éste.

Hoy tuvo lugar la primera sesión de tutoría con un grupo de estudiantes sin experiencia en el ABP. En la primera tutoría se supone que debemos presentarnos y hablar de nosotros. Si bien yo tenía los nombres y las fotos de los miembros del grupo, esto era tan poco informativo como lo son las tarjetas de visita y deberíamos tratar de conocernos mejor cuando estuviéramos cara a cara. ¡Mon dieu!, hablar de uno mismo en frente de extraños no es fácil a menos que seas una persona mayor como mi padre que, como hacen muchas personas mayores, habla sin importarle mucho que lo que diga es apropiado.

A pesar de que fue un poco difícil al comienzo, gradualmente todos dijimos algo de nosotros mismos. Los estudiantes contaron sus experiencias -algunas en el ámbito de la salud-, lo que deseaban para el futuro, sus ambiciones y por qué querían estudiar medicina. Aunque otros tutores no declaraban lo que ellos hacían como profesionales, los estudiantes deseaban saber en qué trabajaba yo. Me pareció importante hablar de ello para crear una atmósfera de confianza y comenzar desde el primer día con transparencia total.

Uno de los estudiantes me dijo: 'he oído que usted es un buen profesor y, por lo que nos han dicho, el profesor en el ABP no enseña, ¿no le gustaría poder enseñarnos todo lo que sabe?'.

Les conté que cuando comencé a trabajar como tutor facilitador en el ABP no me entusiasmaba mucho el no ser un típico profesor como lo era antes. Y ni siquiera creía que todo lo que los estudiantes deberían aprender se podría hacer a través del ABP; había que darles clases para 'cubrir todo el contenido de la asignatura', frase que yo conocía muy bien. Como conocía muy bien el sistema de enseñanza del que fui parte por muchos años. 'Viví en el monstruo y le conocía las entrañas.' Sin embargo, yo, como la mayoría de mis colegas, sabíamos que debíamos cambiar nuestra manera de pensar para hacer que nuestra tarea docente fuera más efectiva y estimulante para los estudiantes. Pero siempre encontrábamos coartadas para posponer cualquier cambio diciendo 'no aún', como dijo san Agustín tras pedir a Dios que le diera castidad y abstinencia. La dilación no es algo ajeno al humano y las resoluciones de cambiar, incluso las que hacemos al comienzo de cada año, son, en general, muy agustinianas. Preferimos posponer las cosas desagradables o difíciles para el futuro, aunque su coste inmediato sea mínimo.

Cuando hice los cursos de formación en ABP, al principio me costaba cambiar de ser profesor que enseña a tutor que facilita. Justificaba mis intervenciones utilizando palabras como conducir, reconducir, guiar; todos estos eufemismos que reflejaban mi necesidad de controlar y evitar incertidumbres. Luego comencé a comprender mejor mi rol y a sentirme más cómodo en él. Llegaría el momento de tener que poner en práctica lo aprendido, porque como dijo Sancho a Don Quijote: 'al freír de los huevos lo verás. Tenía la ansiedad de un novato que en los cursos de formación se sintió capacitado, pero ahora enfrentado a la realidad, la cosa era distinta y sabía que el proverbio de Camden sería mi realidad: 'All the proof of a pudding, is in the eating.

Comenzamos con el primer problema, que más que un problema era el enunciado de una situación. Nuria comenzó a leer la situación y al final de la primera frase fue interrumpida por Jordi, quien afirmó saber de qué se trataba. Les dije que podían enfocar el estudio de cada problema como lo desearan, pero que un texto sólo se comprende en su totalidad cuando se lee en su totalidad. Acordaron leer el texto completo de la situación -el cual era bastante breve- para tener una idea más acabada de lo que se trataba.

Aunque creí que les había explicado que en esta primera sesión deberían identificar lo que deseaban aprender para comprender mejor la situación y finalizar con objetivos que constituían su plan de estudio, los estudiantes dijeron que no estaban seguros de lo que deberían hacer. La confusión parecía ser total.

Reconozco que yo mismo me sentí como viajando en el castillo ambulante de la película de Miyazaki, que se movía de forma tambaleante sin tener un rumbo claro. Los estudiantes se preguntaban: ¿qué se espera que hagamos?, ¿qué debemos estu- 
diar?, ¿cuál es la diferencia entre los objetivos de aprendizaje y los objetivos de nuestro plan de estudio? Decían que era como completar un rompecabezas sin tener en frente como guía la foto del producto final. Esto me recordó cómo me sentía yo al comienzo de mi formación en ABP.

Como no debía darles los objetivos de aprendizaje al inicio para que expresaran su creatividad y no se sintieran limitados, noté que los estaba llevando a través de un callejón con poca luz que debían recorrer sin saber lo que les esperaba a la salida. Cuando me pidieron que les dijera lo que debían aprender, traté de explicarles por qué en el ABP se trataba de simular la situación real en la cual los problemas no vienen con una lista de lo que se debe saber y aprender para su mejor comprensión. Les dije que los objetivos los tendrían tras haber hecho ellos mismos un plan de trabajo, un plan de estudio. De esta manera verían que lo que identificaron para aprender iba a ser, en su gran mayoría, lo mismo que los profesores deseaban que ellos aprendieran.

Traté de instilarles confianza diciéndoles que ellos se sienten como yo me sentí en mi primera experiencia en el ABP. No estoy seguro que ello los ayudara mucho, puesto que no me resultó fácil disimular mi nerviosismo e inseguridad.

Finalmente elaboraron un plan de estudio con objetivos basados en la lista de temas que surgió durante una lluvia de ideas. Como me esperaba, estos objetivos identificados por los estudiantes eran en su gran mayoría los mismos que los que planificaron el módulo nos instruyeron como innegociables.

Fue una sesión dura y me dejó la sensación de que cometí muchos errores que lamentablemente no estaba seguro de cómo corregir. Al hablar de esto con Marta, que era tutora al mismo tiempo que yo, ella me dijo que se sintió de la misma manera; no sabíamos realmente qué debíamos hacer; lo que compartimos fue nuestra incertidumbre y ansiedad.

\section{Miércoles, 9}

Hoy tuvimos la segunda sesión de tutoría para el mismo problema.

Empezaron con presentaciones orales de lo que habían estudiado. Algunos utilizaron su ordenador, del que leían la información que habían encontrado. Otros hicieron presentaciones en PowerPoint leyendo las diapositivas que proyectaban. No hubo una dinámica de compartir y se siguió un orden formal de presentaciones aunque parte de la información había sido encontrada por más de uno de los estudiantes.
A la mitad de la sesión dijeron que se estaban aburriendo y que de esa forma no aprendían mucho desde que estaban pendientes de cuándo les llegaría su turno, sin verdaderamente prestar atención al compañero que hablaba. Era también obvio que lo único que habían hecho algunos estudiantes era haber recogido la información pero sin analizarla o demostrar comprensión de ella. Leían algo que habían sacado de distintas fuentes, incluyendo la Wikipedia y los apuntes de sus amigos estudiantes de otras facultades. No hubo un análisis crítico de las fuentes de información y de la fiabilidad de lo encontrado. Yo lo consideré un desastre y que fue mi culpa que ocurriera puesto que había dejado que ellos mismos encontraran el mejor método de compartir la información. Esto lo hice notar y les pedí que pensaran un mecanismo alternativo del manejo de la información en las sesiones de tutoría.

Acordaron que el compartir las fuentes de información era lo importante y que un breve resumen de lo esencial era suficiente. También se pusieron de acuerdo en que más que presentaciones, lo importante era discutir con la participación de todos. Reconocieron que si bien las presentaciones usando PowerPoint los hacían sentir más seguros, finalmente acababan leyendo lo que se proyectaba en la pantalla -modelo quizás aprendido de sus profesoresy no el hacer una reconstrucción o síntesis de la información utilizando sus propias palabras. Aceptaron que esto último demostraría comprensión y no solamente saber leer. Dijeron, como una de esas bromas que duelen por ser demasiado cercanas a la verdad, que sospechaban que durante las presentaciones alguno de sus compañeros estaba consultando su correo electrónico en el ordenador donde se supone que debería estar haciendo anotaciones.

El resumen que acordaron hacer era decir de forma concisa lo esencial, una tarea que encontraron difícil; sabían que lo más difícil era ser conciso, y con un guiño de complicidad uno de ellos me dijo que no había encontrado buenos ejemplos entre los profesores.

El resto de la sesión fue muy dinámica, con un buen intercambio, confirmando, pero también desafiando, la información brevemente presentada. El uso del ordenador portátil fue infrecuente pero adecuado porque se utilizó para mostrar esquemas, diagramas o figuras que apoyaban lo que discutían. De forma espontánea, uno de los estudiantes se ofreció para compilar las referencias aportadas por todos y se comprometió a hacer una lista que distribuiría entre todos o colgaría en la página web.

Se pusieron de acuerdo en que cada uno debía estudiar fuera de la tutoría aquellos temas de los 
que no fueron responsables cuando se dividieron el plan de estudio.

A pesar de mi alto nivel de ansiedad y que en varias ocasiones tuve la tentación de intervenir diciéndoles lo que yo consideraba correcto, no lo hice dejando que llegaran a estas conclusiones por ellos mismos, a veces cometiendo errores de los cuales parecían aprender.

Me pidieron que resumiera lo discutido, pero fui capaz de convencerlos de que deberían ser ellos quienes lo hiciesen. Esto les permitiría tener una idea de la comprensión de lo trabajado y al mismo tiempo me serviría para evaluar el trabajo realizado y la fiabilidad de las fuentes de información.

Preguntaron cómo sabrían si el nivel de profundidad del conocimiento que adquirían era el adecuado. Les sugerí que una de las maneras de hacer esto es volver al problema y aplicar lo aprendido para ver si ahora lo comprendían mejor.

Comentaron que no creían haber sido eficientes en el uso del tiempo durante las tutorías, que sentían que el ritmo de trabajo era demasiado lento y que el tiempo no se utilizaba bien desde que se entablaban demasiadas discusiones y debates. Me dijeron que los ayudaría a ahorrar tiempo si yo les decía qué era lo que debían estudiar con respecto al problema y cuál era el camino correcto que deberían seguir.

No me resultó nada fácil resistir a esa petición e intenté convencerlos de que si bien parecía que se había utilizado mucho tiempo, realmente no fue así. Y que, además, el proceso que seguían los ayudaba a aprender cómo aprender y que con el tiempo se volverían más eficientes.

\section{Jueves, 10}

Como me pasa a menudo, me asaltaron dudas de lo que hago que comparto con mi mujer, la cual me ha dado a leer el poema Nudos de su colega poeta y psiquiatra R.D. Laing. No estoy seguro de si lo hizo para que yo entendiera cómo se sienten los estudiantes o para que considere los riesgos en lo que estoy haciendo. Me dijo que las últimas estrofas del poema seguramente reflejaban lo que podrían estar pensando los estudiantes:

No sé lo que sé

y que sin embargo debería saber.

Así que tendrás que decírmelo todo.

Los estudiantes esperan el tipo de guía que dan las clases, donde los profesores exponen su conocimien- to y los estudiantes llegan a la conclusión que eso es lo que deben saber, particularmente para pasar con éxito los exámenes.

\section{Viernes, 11}

Hoy finalizamos el primer problema.

Trato de resistir la tentación de 'decírselo todo', pero peccavi, mea culpa! No pude resistir el explicarles mucho más allá del punto concreto que me pidieron que les aclarara en mi área de conocimiento. Tras un tímido inicio, me levanté como poseído por una fuerza incontrolable, fui a la pizarra y mi explicación se convirtió en una clase expositiva. La única diferencia con mis clases del pasado fue que mi audiencia eran los diez estudiantes de mi grupo y no toda una clase. ¡Incluso les ofrecí darles unos apuntes sobre el tema!

Reflexionando sobre lo que hice, me di cuenta de que lo que les expliqué era lo que yo ya había decidido, en mi rol de docente experto, que iba a incluirse en el examen. Mi grupo tuvo una injusta ventaja sobre el resto porque oyeron 'from the horse's mouth' lo que se espera que deben saber para el examen; los aventajé con respecto a sus compañeros de clase. Tal vez inadvertidamente, hice dos transgresiones: una fue distorsionar el rol del tutor, rol acordado en la institución ante la cual soy responsable. La segunda, y la que me causa más aflicción, es que aventajando a mi grupo crucé la delgada línea que separa lo apropiado de lo inapropiado en la equidad que debe regular nuestras acciones como docentes.

¿Por qué lo hice? Probablemente no sea capaz de analizar por separado las distintas razones que podrían explicar mi comportamiento. ¿Sucumbí a mis dudas de que los estudiantes sean capaces de aprender lo que se espera y me permití decidir que la mejor manera de hacerlo es que yo lo enseñe? Aunque lo niegue de forma enfática, sé que todavía echo de menos el protagonismo que disfrutaba cuando daba clases.

Me ha sido muy difícil controlar mis impulsos, esos impulsos de cuidar que están tan arraigados en ser un padre y un maestro. Tengo el temor de que, como le sucedió a Ícaro, vuelen demasiado alto, y que sus alas se desprendan y caigan al mar con su resultado catastrófico. Cuando me siento de esta manera encuentro que la tentación de intervenir es irresistible.

En una de nuestras vacaciones estuvimos en Bruselas y fuimos al Museo de Bellas Artes. Recuerdo que el mirar el cuadro de Brueghel, Paisaje con 
la caída de Ícaro, me hizo reflexionar sobre lo que significa ser indiferente ante el desastre. Temo que mi comportamiento como facilitador sea interpretado por los estudiantes como indiferencia. El poema de Auden basado en el cuadro de Brueghel es sobre la indiferencia frente a la catástrofe:

\section{Todo se aleja pausadamente del desastre; el labriego con su reja pudo oír el chapuzón, el grito desolado, pero para él no era importante; el sol brillaba sobre unas piernas blancas que se hundian en agua verde, y desde el costoso barco delicado veían lo prodigioso: un chico del cielo defenestrado; pero el barco seguía su rumbo y con calma navegaba.}

Deseo que los estudiantes comprendan que no soy indiferente a las dificultades que ellos tienen en el ABP, y que impediré que por mi culpa caigan al mar del fracaso; pero no estoy seguro de si me creerán.

En la segunda parte de la sesión llevamos a cabo la evaluación de lo observado en las sesiones de tutoría. Intenté hacerles comprender la importancia del proceso que involucraría autoevaluación y la evaluación por sus compañeros, además de mi propia evaluación de ellos. Les expliqué que en un proceso formativo en el cual el énfasis está en el aprendizaje autorregulado, que los estudiantes tengan oportunidades para hacer autoevaluación resulta esencial para poder monitorizar y reflexionar sobre el progreso que llevan a cabo. También les mencioné que el tener oportunidades para evaluar y hacer comentarios sobre el progreso de sus compañeros se ha demostrado efectivo para desarrollar habilidades de evaluación que se atienen a los estándares preestablecidos.

Tras estas palabras de introducción comenzamos la evaluación, la cual es siempre un proceso difícil que crea un nivel alto de ansiedad. Esta ansiedad se incrementa con la evaluación en el ABP, ya que hay muchas incertidumbres y los estudiantes tienen miedo a lo desconocido.

$\mathrm{Al}$ comienzo este proceso fue difícil y visto con temor. Tener que autoevaluarse creó mucha ansiedad. Que tuvieran que evaluarse entre ellos y que yo también tuviera que evaluarlos les dio pánico, sentimiento individual pero contagioso, lo que se convirtió en un pánico colectivo. Yo sabía que hacer este proceso de forma honesta y productiva requeriría tiempo. Como a menudo habían argumentado y discrepado entre ellos, entiendo que se sintieran inseguros y vulnerables con la evaluación que hacían unos de otros. Les había pedido que vinieran preparados y que releyeran las anotaciones que ha- bían tomado durante las tutorías y también los criterios de evaluación que la institución había acordado aplicar. Les recordé que debían centrarse en los hechos y no en las personalidades, y ciertamente no hacer interpretaciones de las posibles intenciones detrás del comportamiento de cada uno de los miembros del grupo.

La evaluación que hicimos en el grupo resultó mucho mejor de lo que me esperaba. Tuve que, de forma hábil, desafiar la tentación de apoyarse mutuamente sin ser críticos. Cuando los comentarios sobre ellos mismos o sobre los miembros del grupo no pudieron sustentarse con ejemplos, los forcé a que los justificaran, sobre todo cuando mis observaciones no correspondían con las de ellos. En algunas ocasiones corrigieron mis propias observaciones porque las consideraron erróneas o incompletas. A través de este proceso reconocieron que deberían ser honestos y ser capaces de identificar tanto las áreas fuertes como las débiles y si fuera posible dar sugerencias para corregir estas últimas. Fue evidente el mérito de la autoevaluación y de la coevaluación porque en ambas hay elementos de los que solamente la persona implicada puede hablar.

También fue evidente la ventaja de la evaluación conducida con este modelo de transparencia para poder establecer el diálogo -no solamente la transmisión de información- entre el estudiante, sus pares y el profesor sobre el desempeño de cada miembro del grupo. En el modelo de diálogo, el estudiante no sólo recibe información sobre su rendimiento, sino que se entabla una discusión entre todos los involucrados. Esto ha permitido no sólo identificar las fortalezas y debilidades, sino también transmitirles recomendaciones para la corrección de estas últimas. Además, la ventaja adicional de ese diálogo fue que los ayudó a entender los estándares y expectativas, corregir posibles malentendidos y obtener una respuesta inmediata para una posible solución a los problemas encontrados.

\section{Viernes, 18}

Tras finalizar el segundo problema me preguntaron si después de tanto trabajo yo opinaba que estaban aprendiendo algo útil. Les dije que quizás ayudara el repasar lo que se había convertido en un libro de inventarios. Regularmente, tras finalizar cada problema, habían anotado qué objetivos de aprendizaje habían cumplido, lo que les permitía evaluar por ellos mismos su progreso. Así lo hicieron y se sorprendieron al ver lo mucho que habían aprendido y cuántos objetivos habían cumplido. 


\section{Viernes, 25}

Hoy fue la tercera y última sesión del tercer problema. Los estudiantes se han dado cuenta de que llegar a una meta requiere un duro trabajo, pero piensan que han demostrado poseer las habilidades necesarias para escalar y llegar a lo más alto; que el esfuerzo individual y cooperativo les haría llegar a donde se proponían y que son capaces de cumplir con las tareas asumidas; también se habían dado cuenta de que cuando los profesores les decían a ellos que no sabían nada de un tema, aceptaron este juicio, pero estaban equivocados. Habían aceptado que sus cabezas eran como botellas vacías dentro de las cuales los profesores deberían verter conocimientos. Se dieron cuenta de que el conocimiento que ya tenían, conjuntamente con sus experiencias, era parte de lo valioso que aportaban a las discusiones del grupo. A menudo se vio que el conocimiento que poseían estaba desorganizado y lo que necesitaban era organizar mejor lo que ya estaba ahí, profundizar, ampliar y corregir lo erróneo, pero que sus cerebros no eran como botellas vacías. Dijeron que ahora se sentían más seguros y con menos ansiedad.

Cuando dijeron que el ABP era duro, les conté que a mediados de los años ochenta, en una escuela de enseñanza primaria de un barrio de San José, en California, se introdujo a los alumnos el aprender a programar en ordenadores utilizando el lenguaje Logo -un lenguaje de programación-. El método consistía en presentar a los niños retos intelectuales que podían resolverse mediante el desarrollo de programas en Logo. El proceso de revisión manual de los errores cometidos en la programación contribuía a que los niños desarrollaran habilidades metacognitivas al poner en práctica procesos de autocorrección. Uno de los maestros oyó a niños decir: 'It's fun. It's hard.' No que a pesar de ser duro es divertido, sino que es al mismo tiempo ambas cosas. De esta manera surgió la idea de que el ABP es difícil y duro, pero es divertido, y que esta idea de diversión y trabajo duro era la dualidad universal del yin y del yang aplicada al ABP.

Los estudiantes me han preguntado por qué no implementamos un método de ABP con una estructura más definida, con un andamiaje que les marque un camino más certero de a dónde ir y qué hacer; han oído que esto lo hacen otras instituciones en Europa. Mi respuesta fue que en los casos en los cuales se ha creado la superestructura del andamiaje es como transitar por una autopista en la cual todo está previsto y el paisaje diseñado alrededor de ella -los arbustos en la mediana- es atractivo pero crea monotonía. Los valles y los ríos son obs- táculos que se superan con viaductos y puentes que no permiten apreciarlos. Las praderas y los campos cultivados se ven a la distancia como diseños de figuras geométricas de verdes y negros, atractivas a primera vista, pero monótonas. Todo esto acarrea el riesgo de que el conductor se distraiga a menos que aparezca algo que le haga prestar más atención, como un peaje. El ABP es como transitar por un camino rural donde se circula más lentamente pero se aprecia el paisaje gracioso y ondulante que lo rodea. Se requiere más tiempo porque se debe transitar por pueblos, aldeas y villas, algunas muy atractivas, pero siempre idiosincrásicas. La variedad y belleza de la flora que rodea el camino tiene la atracción de ser cambiante. Aquí se atraviesan ríos, riachuelos, puentes antiguos -algunos en desuso por la construcción de autopistas- de hierro, madera, a veces de hormigón; todos obligan a reducir la velocidad y apreciar la belleza de la corriente de agua sobre la que se pasa. La atracción de lo inesperado siempre está presente y el aburrimiento es menos probable. Esto tiene congruencia con lo que se ha dicho de la pedagogía: es un tipo especial de encuentro erótico, una reunión del maestro y el estudiante en el cual éste puede encontrar regocijo en el aprendizaje de algo nuevo para su propia satisfacción. Los estudiantes pueden hallar placer en sus deseos de adquirir más conocimientos y convertirse en más diestros, sabios, poderosos o competentes. Y además pueden disfrutar el satisfacer con éxito las expectativas de los profesores. Pero a veces, el maestro y el estudiante saben de memoria todos los pasos de la danza pedagógica y hallan consuelo y seguridad en su predecible orden. Entonces, el proceso pedagógico degenera en mera rutina. Demasiado confort, seguridad y previsibilidad anestesian: no se puede ser un sonámbulo a través de la experiencia pedagógica. He tenido la experiencia de que la danza pedagógica es salvaje y caótica, algo a veces alegre, a veces doloroso. Eco y Sebeok, en su libro El signo de los tres -que pienso que es de lectura obligada para los interesados en el proceso de solución de problemas- han descrito el valor de la incertidumbre: 'a medida que decrece la certeza de una conjetura, aumenta proporcionalmente su valor heurístico'. Las superestructuras que han aplicado al ABP aquellos que tienen cero tolerancia a la incertidumbre seguramente han disminuido su calidad ubérrima.

Las comparaciones del ABP con la enseñanza considerada más tradicional no tienen mucho sentido desde que el ABP es una ventana abierta a otro paisaje. En el ABP nos enfrentamos a un trabajo duro que conlleva una transformación de todos, los estu- 
diantes y los profesores. El ABP tiene la capacidad de transformarnos, de cambiar la forma en que aprendemos o enseñamos. El impacto que ha tenido el ABP en mí como docente también lo ha tenido en mí como persona. El proceso de autoevaluación, que es parte de la evaluación formativa del ABP, me ha hecho reflexionar sobre aquellas cosas que me eran fáciles poner de lado y no prestarles atención.

La experiencia en el ABP ha creado en mí el espacio que necesitaba para una reflexión crítica que me ha llevado a una actuación responsable y a una transformación personal en el dividido mundo que habitamos y en lo dividido que es el yo. He llegado a comprender que lo realmente importante es aceptar de manera simultánea lo más optimista y lo más avieso de mi yo. Siento que he llegado a apasionarme con el ABP, no por lo que es, sino por lo que yo soy cuando soy parte de él y por lo que está haciendo de mí y por la parte mía que el ABP es capaz de hacer aflorar.

\section{Octubre}

Sabían que además de la evaluación en las tutorías, los estudiantes deberían hacer una prueba escrita con énfasis en el proceso del ABP -lo que se ha llegado a conocer como 'examen ABP'-, que no sólo evalúa el conocimiento sino también la comprensión de éste. Esto hizo retornar la ansiedad sobre la evaluación. Tenían dudas de si individualmente, de forma independiente del grupo, serían capaces de demostrar ser competentes y haber adquirido conocimiento de aplicabilidad a los problemas presentados. En una prueba en la cual deberían seleccionar lo que consideran importante aprender para comprender mejor el problema y, además, tener que justificar la selección utilizando el conocimiento previo, la falta de familiaridad con este tipo de prueba les preocupaba mucho.

A pesar de que encontraron el examen ABP una prueba más dura de las que estaban acostumbrados, los resultados fueron alentadores y los estimularon a aprender más. A través de esta prueba también se han demostrado a ellos mismos que poseen el componente del talento que se atribuye a las personas jóvenes: una aptitud natural de ser creativos.

Manifestaron tener la duda que es la misma que yo tengo: teniendo en cuenta los aspectos subjetivos de toda evaluación, cómo los profesores podemos ser ecuánimes. Les dije que como grupo docente habíamos acordado corregir las pruebas utilizando criterios preestablecidos. El grupo docente también había acordado que los comentarios que llegaran a los estudiantes debían hacerlo en el momento oportuno, es decir, los estudiantes debían recibir el resultado y el feedback con antelación a tener que presentarse a otra prueba de evaluación.

Lo que he tenido que aprender es cómo, dentro de las restricciones que impone la normativa universitaria, se puede establecer un diálogo de retroalimentación con los estudiantes para poder discutir lo que los profesores hemos identificado como fortalezas y debilidades en su trabajo. Cuando me enfrento a estas normativas no puedo dejar de escuchar el molesto zumbido de las palabras de Ovidio: 'la previsión humana promulgó leyes malignas y lo que la naturaleza admite, lo prohíbe el odioso derecho'. La naturaleza pedagógica de la evaluación no sólo admite sino que demanda algo que las barreras normativas universitarias dificultan. La normativa de mi universidad establece que el trabajo escrito del estudiante no le pertenece a él, lo cual implica que éste no tiene irrestricto acceso a su evaluación. Puede ver el resultado, lo que es equiparable a echar un vistazo, si se presenta a una reunión de revisión de notas con el profesor o los profesores responsables de la evaluación. Las normativas implican que el estudiante, tras haber visto los resultados de su trabajo -notas- a las que ha tenido acceso a través de las nuevas tecnologías o han sido anunciados en carteles pegados con cinta adhesiva en las paredes del departamento, tenga que concurrir a una revisión, que a menudo se convierte en un regateo y no en un diálogo, que es lo que debe ser el feedback. En lugar de que el estudiante tenga acceso a su evaluación incluyendo los comentarios hechos por los evaluadores y que tenga tiempo para pensar y reflexionar sobre ellos, se le fuerza a que, a la mayor brevedad, lea esos comentarios cuando viene a la revisión y, si tiene el coraje, entre en un debate sobre ellos. La reunión de revisión se conoce como aquella actividad donde el estudiante va, en teoría, a ver dónde se equivocó, pero en la práctica, a disputar y regatear la nota que se le ha asignado.

Nuevas tecnologías son de cierta ayuda, como utilizar en los programas para incorporar las notas las columnas correspondientes al feedback del evaluador. Yo he encontrado este sistema de gran ayuda, aunque está lejos de ser un diálogo.

Sabemos que la evaluación debe ser parte del aprendizaje y no el hacer acerbos juicios críticos de desempeño del estudiante. Incluso para aquellos estudiantes que han obtenido la máxima calificación, los comentarios del evaluador pueden -o deben- indicar la exploración de nuevos caminos que pueden conducir a la excelencia. Me he sentido frustrado con la distorsión que ocurre en el proceso 
de evaluación, que raramente se considera otra estrategia de aprendizaje.

\section{Noviembre}

Algunos estudiantes me han preguntado mi opinión sobre una carrera en investigación. El ABP no parece poner énfasis en estas actividades dentro de un área disciplinaria. Les recordé que mucha de la actividad que llevaron a cabo suponía el desarrollo de hipótesis, búsqueda y análisis crítico de la información a través de la cual podrían confirmar o rechazar las hipótesis. Esto, les dije, es el meollo de la investigación y por lo tanto deben considerar que han desarrollado parte de las habilidades requeridas para ser científicos. Sin embargo, es verdad que debido a la integración de las áreas de conocimiento, el ABP puede no dar suficientes oportunidades para explorar los caminos de la investigación en una área específica. Les recomendé que utilizaran las optativas y el trabajo de fin de carrera para explorar sus intereses en investigación.

Además, les conté que Kai Simons, cofundadora y directora del Max Planck Institute of Molecular Cell Biology and Genetics, de jovencita deseaba seguir una carrera de investigación en física. Cuando le pidió consejo a su padre, que era profesor de física en la Universidad de Helsinki, éste le dijo: 'Kai, ¿por qué no estudias medicina en su lugar? Puedes hacer investigación, pero si no te gusta, al menos tienes una profesión.' Kai Simons siguió el consejo de su padre y aunque disfrutó de la carrera de medicina, también se interesó por la fisicoquímica del transporte de moléculas a través de las membranas, convirtiéndose en una de las científicas más reconocidas por su investigación en esta área.

Se sabe que el usar metáforas expresa realmente lo que sentimos. Tras varias semanas de trabajo, utilizando metáforas que yo conocía, les dije que los veía como árboles jóvenes en un bosque, creciendo rápidamente, con nuevas ramas y nuevas hojas. También les dije que yo me veía como un árbol más grande y probablemente más sabio, aunque a veces tenía la impresión de que les bloqueaba el sol que necesitaban para crecer mejor y sentirse más fuertes. En algunas ocasiones me he sentido como un jardinero que de vez en cuando doy fertilizante, pero que también me encargo de podar eliminando lo superfluo para que puedan crecer mejor. Sé que esto a veces ha sido doloroso, pero el resultado demuestra que fue necesario.

En momentos de euforia me siento que debo exclamar como Eneas: mirabile dictu!; sí, es maravi- lloso contar cómo el ABP estimula el aprendizaje. Pero me llevó mucho tiempo poder liberarme de la autoprotección de mi profesionalismo docente para aprender a escuchar lo que realmente decían los estudiantes. La transformación fundamental que he observado en mí es el cambio en la manera en que mis valores profesionales guían mis gestos, mi postura e incluso mis emociones y mi habilidad de discernir quién soy independientemente de lo que mi grupo profesional considera deseable y aceptable.

Ser conformista y no explorar los múltiples caminos que la docencia nos ofrece, acomodándonos a lo que la comunidad docente considera lo normal, es arriesgado para la exploración de mejoras e innovaciones en la docencia. Preparándome para dar una conferencia en la Universidad de Alcalá de Henares sobre innovación en la docencia, y no teniendo total confianza en mi habilidad de estimular a la audiencia, consideré un valioso aguijón el hacer referencia a algún exalumno que fue famoso por la controversia que han despertado sus ideas y su comportamiento; elegí al cardenal Giulio Raimondo Mazzarino quien, en su breviario de los políticos, aconseja hacerse cuatro preguntas, una de las cuales es: 'esta innovación, ¿me será personalmente útil o perjudicial?'. El cardenal Mazzarino continúa alertando sobre si la innovación va a ser apreciada por los que gobiernan. Observar éste y otros de sus consejos que en honor a la ética política -me pregunto si estas dos palabras constituyen un oxímoron- no son aconsejables, es probablemente el factor fundamental que ha resultado en reprimir la innovación en educación médica.

Reconozco que a través del proceso reflexivo que es nuclear al ABP descubrí mi habilidad de analizar críticamente esos estándares de 'normalidad' antes de adoptarlos o, incluso, llegar a confrontarlos y a veces rechazarlos. Después de todo, la comunidad docente que es la academia universitaria puede ser solamente un conjunto de personas que influye en una organización, esfera o actividad social, en beneficio de sus propios intereses.

También he llegado al convencimiento de que el ABP no es una ideología, no es el conjunto de ideas fundamentales que caracteriza el pensamiento de un movimiento pedagógico porque ser ideólogo es preconcebir la realidad; es la 'genuina realidad' la que determina nuestras acciones.

Trabajando juntos -los estudiantes y yo- reconocimos que en la 'genuina realidad' se puede encontrar dolor, frustración, incertidumbre y desilusión. Pero que también se puede encontrar placer, confianza, armonía e ilusiones. La 'genuina realidad' nos puede agotar y disminuir, pero también nos pue- 
de estimular y acrecentar. También aprendimos a reconocer lo que conlleva el saber más, y que como está escrito en el Eclesiastés: 'en la abundancia de sabiduría hay abundancia de irritación, de modo que lo que aumenta el conocimiento aumenta el dolor'

Me he preguntado muchas veces: ¿hago todo lo que puedo?, ¿doy todo lo que tengo? El dudar siempre me ha creado ansiedad porque probablemente socava mi habilidad de controlar. Pero recuerdo las palabras de Henry James, en La edad madura: 'trabajamos a ciegas; nuestra duda es nuestra pasión y nuestra pasión es nuestra misión.

Justamente hoy, que escribo estas notas en mi diario, he finalizado de leer el conmovedor libro de Arthur Kleinman, What really matters. En él, Kleinman postula que la pasión de dudar, esa sensación de incertidumbre, de la necesidad de cuestionar, es el requisito primordial para una vida moral, moral no en el sentido ético de lo que es bueno o malo, sino en un sentido más amplio refiriéndose a aquello que realmente es importante para cada uno de nosotros.

Reconocer la limitación de mi conocimiento no fue algo retórico, sino real, que generó en mi una humildad que me recordó la Apología de Platón. En La muerte de Sócrates, durante su juicio, Sócrates relata que Querefón fue a Delfos y preguntó al oráculo si había alguien más sabio que Sócrates. La pitonisa le respondió que no había hombre más sabio. 'Cuando me enteré de la respuesta -continúa Sócrates- me dije a mí mismo, ¿qué significa este enigma?, porque yo sé que no tengo sabiduría. Tras una búsqueda tratando de encontrar hombres sabios entre los políticos, los poetas y los artesanos, Sócrates concluye: 'He descubierto que la mayoría de los hombres que tienen la reputación de sabios, son tontos, y que otros menos estimados son realmente más sabios. Y que los que son realmente sabios son aquellos que saben que su sabiduría está en que su saber realmente no tiene valor.

Veo el futuro muy prometedor y siento que seguiré disfrutando el yin y el yang que es el ABP, es decir, trabajo duro y placentero. $Y$ en aquellos días en los que las cosas no salgan bien y el cielo aparezca cubierto de nubes borrascosas, pensaré que, como dijo Scarlett O'Hara en Lo que el viento se llevó, 'mañana será otro día'. 